\title{
Feedwell is the heart of a thickener
}

\author{
Jerold Johnson WesTech Engineering, Inc, USA \\ Antonio Accioly WesTech Engineering, Inc, USA
}

\begin{abstract}
Thickeners that produce non-Newtonian underflow suspensions use the same feedwells as with other thickener types. The functions of converting the horizontal momentum of the feed to a vertical flow and the promoting flocculation of the suspended solids are the same for any thickener. The industry has correctly addressed the feedwell design in recent years. The effectiveness of the feedwell design to accomplish these functions has generally been poor in the industry. Short circuiting flows carry the solids into the thickener prematurely before all the suspended solids have been captured. Also these flows generate such force that solids are carried to the overflow launder before settling can occur. Paste thickeners are oftentimes used as the final dewatering stage of the tailings and the main source for process water return. Clarity of the process water is often regulated if discharged and poor clarity recirculates solids that cause a burden on the system. The patented Evenflo ${ }^{\text {TM }}$ feedwell has been installed in all types of thickener in China and around the world with significant improvements to overflow clarity and overall thickener operation. This paper provides case study results of clarity and elimination of short circuiting.
\end{abstract}

\section{Introduction}

The basic objectives or functions of a thickener's feedwell have not changed in over a 100 years; the feed flow energy must be dissipated and directed vertical instead of horizontal and provide conditions to flocculate the solids so to first collect the solids and then settle them. The feed slurry to be thickened often will benefit from dilution to reduce the wt\% solids for optimized floccule generation. There are several methods of self-dilution (feed dilution internal to the thickener with the thickener supernatant). These methods include use of hydraulic head resulting from the difference in water level in the thickener compared to the level in the feedwell. By the use of ports or spillways the clarified water enters the feedwell providing dilution flow. Another method uses the feed stream velocity in an eductor to blend water from the supernatant with the feed stream. For this paper these methods of feed dilution are assumed effective. A brief overview of the current state of the feedwell designs was provided in Paste and Thickened Tailings - A Guide, 3rd edition Chapter 7 (Jewell, 2015). The feedwell design has been simple for many years. Some general features include tangential feed lines and shelfs or deflectors on the exit. However, these feedwells have historically had some short comings.

\section{$2 \quad$ Short circuiting}

A general short coming of feedwell designs involve the feed stream leaving the feedwell prematurely still with a significant horizontal element (Lake and Summerhays, 2012). The flow short circuits through the feedwell and can carry with it particles that have not been properly flocculated. A typical photo giving evidence of this short circuiting flow is seen in Figure 1. The feed flow is more likely to escape the larger the 
feedwell diameter. The surface solids are fine particles that were not collected in the feedwell and follow in the direction of this lost flow. Poor overflow clarity plague thickeners with this issue.

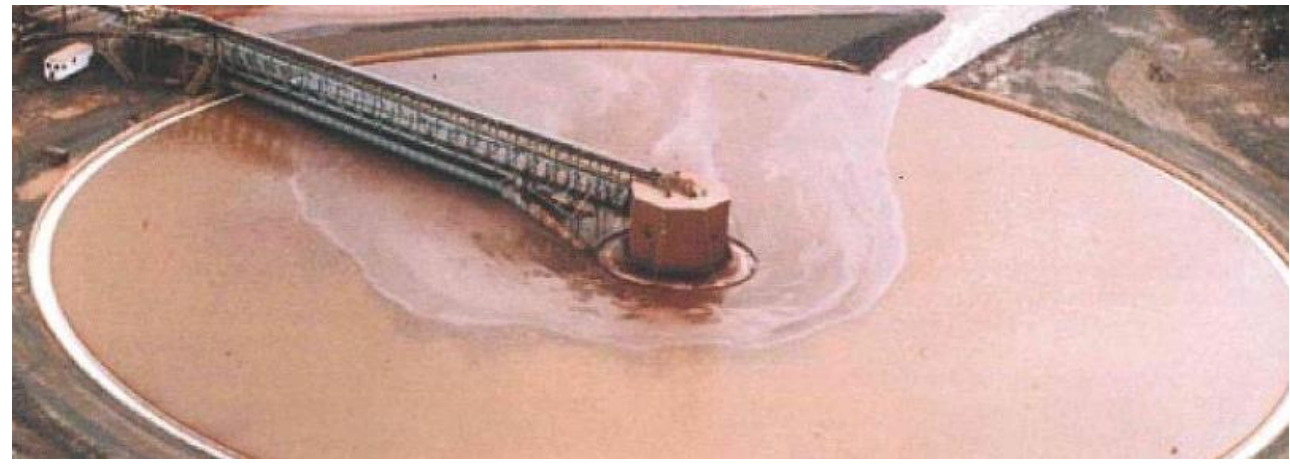

Figure 1 Un-collected fines short circuiting to the overflow

The premature release of the feed stream from the feedwell was also shown to be able to carry the heavier solids of floccules to one side of the thickener (Cook, 2015). This generated a 'sand bar' to one side, which was easily discernible with the manual bed level method. In addition, the bed instrument discussed in the Cook paper showed a bed that had a dense island in this short circuited flow direction and the other half of the bed had light flocculated fines.

\section{$3 \quad$ Mixing required}

The ability for good flocculation in feedwell has also been studied. This topic was part of the focus of a study by CSIRO and AMIRA P266 thickener projects (privately funded and sponsored by industry and manufacturers) to better understand feedwell performance (Jewell and Fourie, 2015). The ability to capture the solids and generate floccules that have the desired settling rate is very sensitive to throughput, and inlet velocity is a crucial parameter in this.

The general result of premature feed flow exiting the feedwell increases as the entrance velocity decreases. However, the faster the feed velocity, the more shear present to break-up the floccules. AMIRA study, using CFD, determined the potential for floccule generation for several of the generic feedwells in the industry. Figure 2 is data from the P266 report (Figure 9).

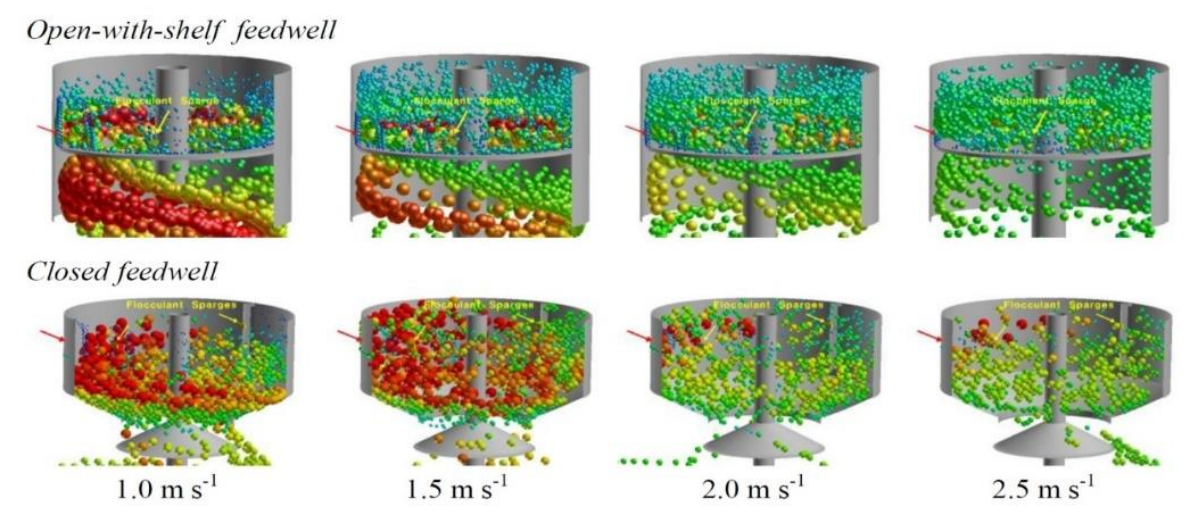

\section{Figure 2 Floccule generation from AMIRA P266 report (Figure 9)}

The size of the floccules is shown in both size and colour. The increase in velocity seemed to have a greater effect on the open-with-shelf feedwell than on the closed feedwell. The floccules size distribution inside either of these two general feedwell types has wide distribution with large and small floccules. The floccules size distribution exiting the closed feedwell has a lack of larger floccules. The open-with-shelf feedwell shows large floccules generally only under the shelf. 
In general, the study does show the importance of proper mixing for floccules generation and that the mixing is supplied by the feed velocity. There can also be too much of a good thing and the shear will break the floccules with excess feed velocity.

\section{$4 \quad$ Industry focus}

There has been an increase of research and development focused on the feedwell in recent years. The thickener suppliers understand that as the feedwell performs the thickener will follow. The short comings of traditional feedwell discussed in the background have been addressed in multiple ways. Feedwell designs like the Outotec Vane Feedwell ${ }^{\mathrm{TM}}$, the FLSmidth E-Volute ${ }^{\mathrm{TM}}$ and the WesTech Evenflo ${ }^{\mathrm{TM}}$ have been introduced in recent years. The short comings of premature feed flow loss and optimal floccule generation have been addressed with the use of tapered feed shelfs that allow the feed flow in the centre of the feedwell gradually to address the short circuiting. Vanes have been installed to create zones with in the feedwell, with the upper zones having more shear than the lower zone. The authors are not familiar with the Outotec and FLSmidth designs and literature searches produce only the brochure type disclosure. Therefore, a discussion of the benefits of these designs is not provided in this article. The reader is encouraged to seek information directly from the suppliers of this technology.

\section{$5 \quad$ Two stage feedwell}

The patented WesTech Evenflo ${ }^{\mathrm{TM}}$ is a design that uses an inner feedwell that communicates with an outer feedwell through radially ports that direct the feed flow radially out toward the outer feedwell wall. This simple addition to an open-with-shelf feedwell has shown to provide great benefits in correcting the short comings discussed above.

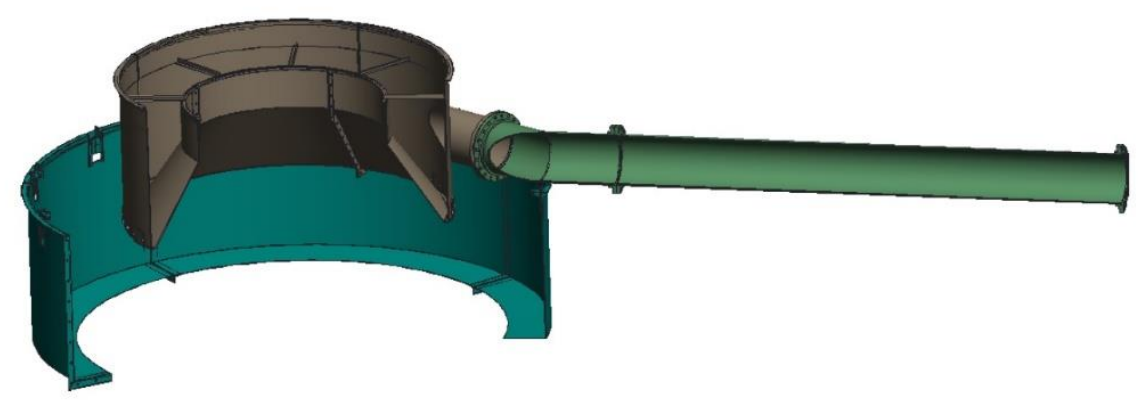

\section{Figure 3 Evenflo $^{\mathrm{TM}}$ diagram cut away}

The feed flow energy is dissipated and converted to radial flow out of the inner feedwell. The inner feedwell ports are sized to have the design exit velocity for the range of feed volumetric flow rate experienced at the thickener. The fact that the feed into the outer feedwell is directed radially provides a large volume with optimal mixing within the feedwell. The exit velocity from the inner feedwell is designed to be at the $1.0 \sim 2.5 \mathrm{~m} / \mathrm{s}$ range. Figure 4 shows the velocity leaving the inner feedwell and the velocity when the flow reaches the outer feedwell wall. The CFD model shown in Figure 4 shows that with the inner feedwell exit velocity of about $1.4 \mathrm{~m} / \mathrm{s}$ the velocity when it reaches the outer wall of about $0.5 \mathrm{~m} / \mathrm{s}$. 

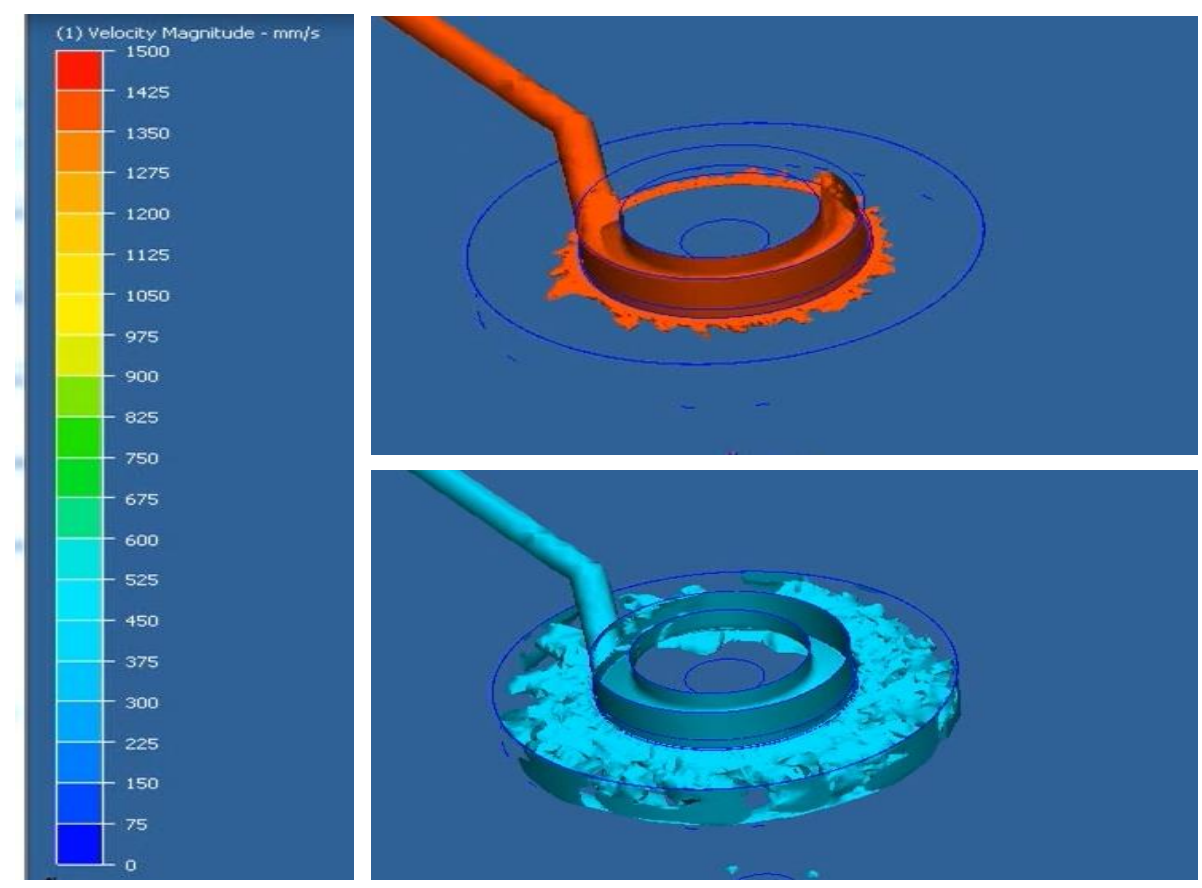

Figure 4 Velocity range across the mix area in the outer feedwell

AMIRA conducted a CFD study of this two stage feedwell, similar to that reported in their P266 project. The results are shown in Figure 5. The design tested was for a $14.5 \mathrm{~m}$ feedwell in a $100 \mathrm{~m}$ high rate thickener. The inner feedwell diameter is about $8.5 \mathrm{~m}$. The flow rate was varied from 9,000 to $17,000 \mathrm{~m}^{3} / \mathrm{h}$. The study included determining the solids distribution, vertical element of the flow velocity, shear rate, distribution of unabsorbed flocculant and then the distribution of the floccules.

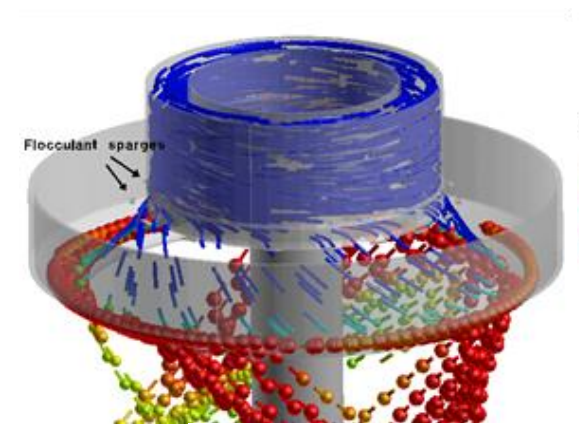

Low flow

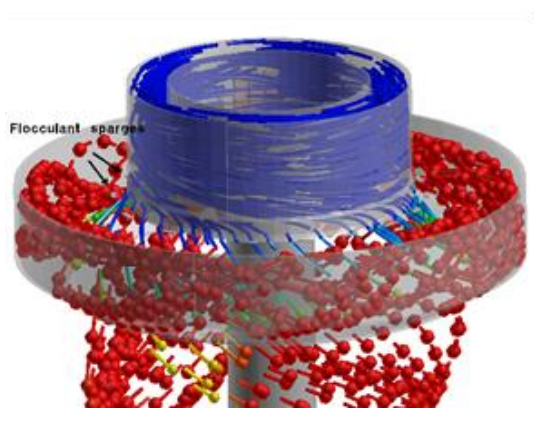

Design flow

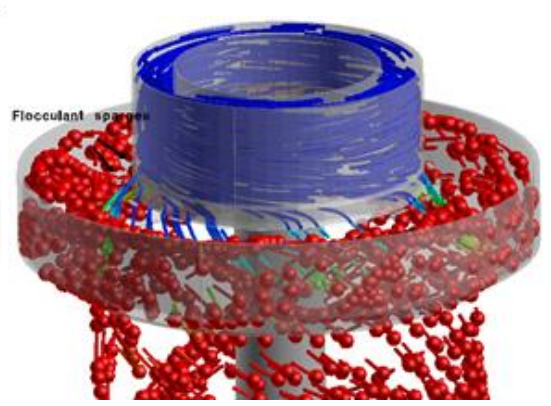

High flow

Figure 5 Two stage feedwell floccule generation over range of feed velocity

This study shows that this two stage feedwell design produces a very consistent mix and produces uniform floccules size over a wide range of feed conditions.

The volume with optimal mixing is increased with this design. The full area outside the inner feedwell has good and consistent mixing. This larger mix volume gives time to 'sweep' the particles from the slurry producing uniform floccules for settling and excellent clarity.

\section{$6 \quad$ China-case study}

Excellent overflow clarity has been produced with these two stage systems. For example, at the ZiJin gold plant in south-eastern China, their water treatment plant precipitate is dewatered in a WesTech Deep Bed ${ }^{\mathrm{TM}}$ paste thickener equipped with an Evenflo ${ }^{\mathrm{TM}}$ two stage feedwell. The mixing zone in the feedwell and the clarified water are seen in the Figure 6 . These photos were taken at design flow rate. The required 
feed dilution is accomplished by self-dilution ports in the outer feedwell. This method of self-dilution uses the difference in density between inside and outside the feedwell. This thickener was designed to dilute the feed from 5 to 8 wt\% solids to a diluted concentration of $2 \sim 3$ wt\% inside the feedwell; a dilution factor of about 3.

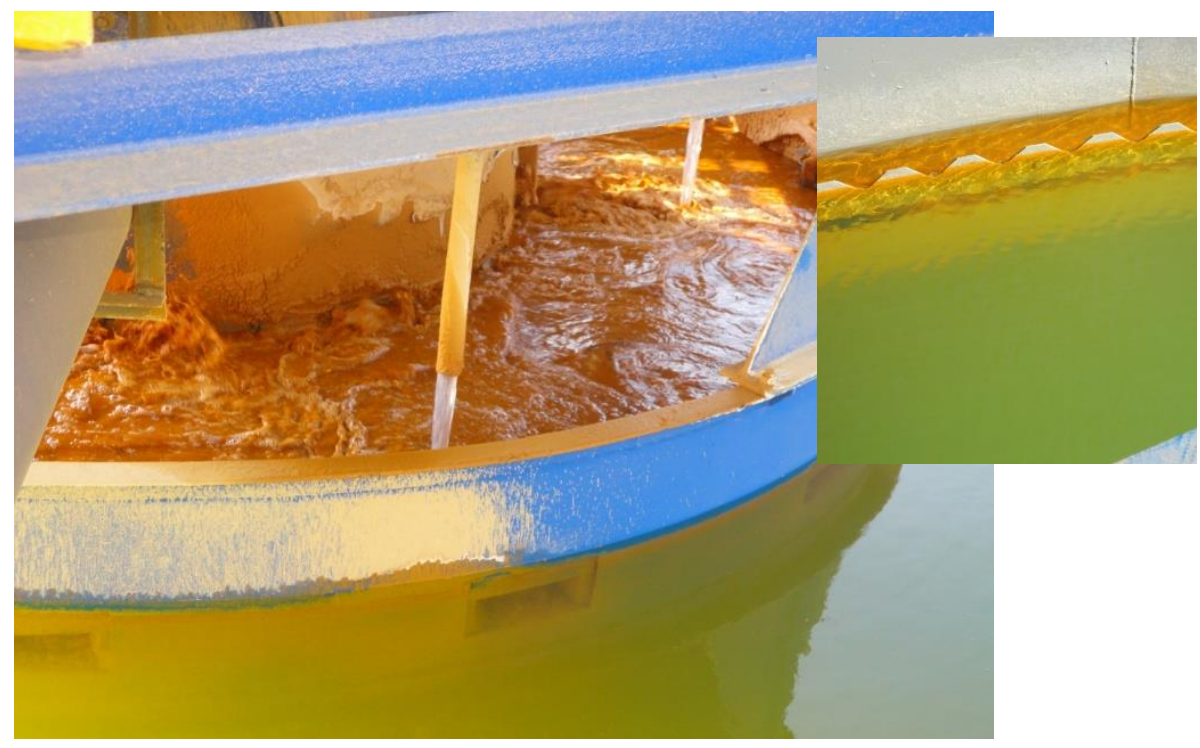

Figure 6 Gold process water treatment stream dewatering in Evenflo ${ }^{\mathrm{TM}}$ feedwell

\section{$7 \quad$ New Caledoni-case study}

The Vale Goro Mine, nickel laterite tailings thickener $(26 \mathrm{~m})$ is dewatering the tailings stream with the goal of discharging the overflow water to the ocean. The suspended solids requirement for discharge is $35 \mathrm{ppm}$. To insure the target was met the plant installed sand filters as the second stage clarification. The plant has been operating for $>6$ months and the filters have not been needed. The overflow clarity produce from the Evenflo $^{\mathrm{TM}}$ feedwell has been lower than target suspended solids. Figure 7 shows the overflow clarity at design flow. The clarity was measured at $13 \mathrm{ppm}$.

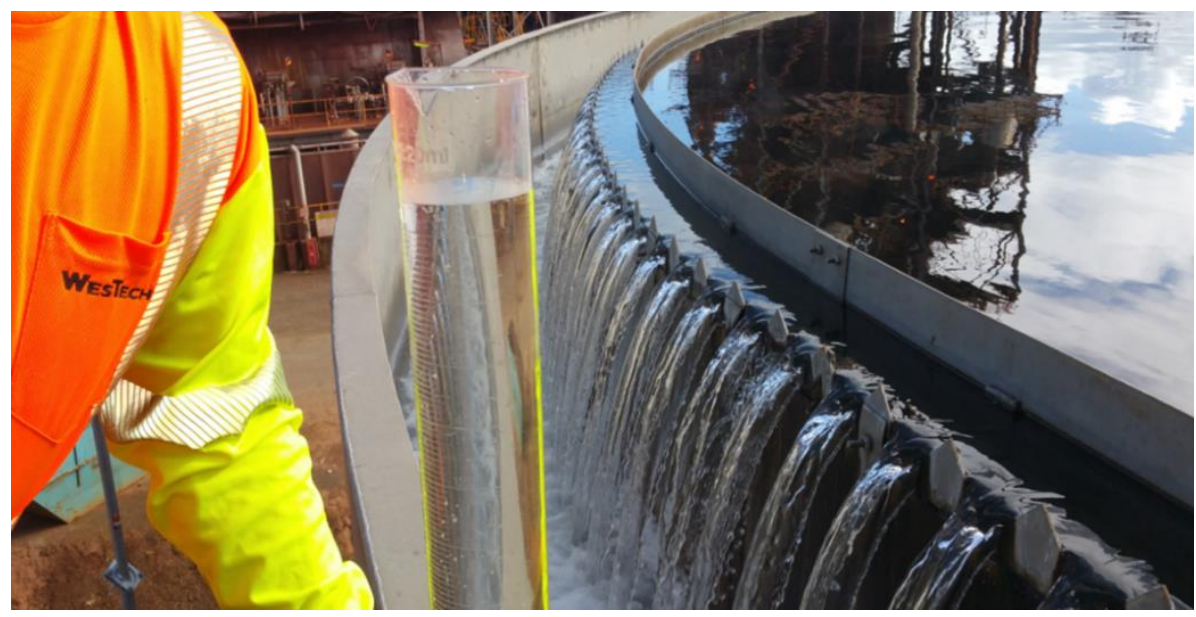

Figure 7 Vale Goro - New Caledonia tailings stream dewatering in Evenflo ${ }^{\mathrm{TM}}$ feedwell

\section{Conclusions}

The performance of a thickener is dependent on the feedwell's ability to dissipate the feed stream energy, convert the flow to a vertical direction and effectively flocculating the solids. Feedwell designs used for 
decades have some inherent short comings. The problem of a portion of the feed flow prematurely exiting the feedwell can carry with it solids. The solids can short circuit to the overflow or even produce a dense 'sand bar' in the bed in the direction of this lost flow. This problem and the ability to produce optimum flocculation can be affected significantly by the feed inlet velocity, which can varying with operating conditions.

Several methods have been introduced to address these problems. One successful method is the use of two stage feedwell. The Evenflo ${ }^{\mathrm{TM}}$ provides a large zone with excellent mixing that produces consistent size floccules and sweeps the solids form the flow producing excellent clarity.

For a properly diluted feed stream the flocculation requirements focus on three main areas; 1 ) selection of the proper flocculant type, 2) flocculant dosage, and 3) mixing. The optimized mixing provided by the Evenflo $^{\mathrm{TM}}$ two stage feedwell now allows the plant to optimize the dosage for their site.

\section{References}

Cook R.D. and Johnson, J.L. 2015, 'A novel method to locate and profile the bed of a thickener', in RJ Jewell \& AB Fourie (eds), Proceedings of the 18th International Seminar on Paste and Thickened Tailings, Australian Centre for Geomechanics, Perth, pp. 45-53.

Jewell, R.J. and Fourie, A.B. 2015, 'Thickening', in R.J. Jewell and A.B. Fourie (eds), Paste and Thickened Tailings - A Guide, 3rd edition, Australian Centre for Geomechanics, Perth, Australia.

Lake, P. and Summerhays, R.P. 2012, 'Thickener feed system design, XIII'. International Mineral Processing Symposium, Bodrum Turkey. 